\title{
A Review of School Bullying
}

\author{
Zilu $\mathrm{Li}^{1, \dagger}$, Xintong Meng ${ }^{2, *}, \dagger$, Jiawen Zhang ${ }^{3, \dagger}$
}

\author{
${ }^{1}$ Western Oregon University, OR, United States \\ ${ }^{2}$ Michigan State University, MI, United States \\ ${ }^{3}$ Washington State University, WA, United States \\ *Corresponding authoremail: mengxint@msu.edu
}

These authors contributed equally.

\begin{abstract}
Most studies have demonstrated that school bullying is a common phenomenon around the world. An important aspect of reducing and preventing school bullying is understanding and determining interventions and strategies to prevent school bullying. Research in the past 40 years has revealed the nature and extent of this behavior and has begun to point out for us that different factors and preventions have certain degrees of impact on school bullying. This review introduces the development history of the management and prevention of bullying in countries worldwide, provides an introductory summary of the research on the relationship between the school learning environment and school bullying, and some popular preventions of bullying behavior are overviewed. Reducing school bullying is a key focus of schools, educators. This review aims to provide schools and educators with a framework based on bullying and education guidelines to better understand the emergence of such behaviors. At the same time, provide schools with some effective intervention measures to prevent or reduce school bullying.
\end{abstract}

Keywords: School bullying, school learning environment, bystander effect, anti-bullying program, prevention

\section{INTRODUCTION}

Bullying is defined as a long-term, systematic, and repetitive pattern of violence that exists among peers. It could happen at any time and anywhere [1,2]. Globally, bullying involves different forms that include cyber and physical bullying. The development of technology as a communication method has led to increased cyberbullying behavior, such as making some harass others in social networking [2]. Bullying is a significant problem in many countries of the world. There are many types of bullying. Verbal and physical bullying is the most common phenomenon. In the research by Marshall et al., whether the victim or the abuser, it affects their physical health and influences their mental health [3]. Regardless of the level of participation, bullying has a serious negative influence on adolescents' health and academic performance [2]. Bullying behavior is a kind of antisocial behavior. It is against social behavior norms and moral rules and has a great impact on social harmony and stability, social fairness, and justice.

In the world of bullying, we usually pay more attention to the phenomenon of school bullying because of teenagers. School bullying is a physical or verbal attack on students in a power-imbalance relationship. Most violence appears in schools and other places where teenagers congregate, which is an aggressive behavior involving students as participants inside and outside campus [3-5]. School bullying is described as victimization and threat of students by other peers of students on campus. Repeatedly and frequently victimized or threatened by other powerful peers can cause the affected students to receive more psychological effects [2]. Chronic bullying can also lead to serious mental health problems, such as depression disorder, suicide, anxiety, and even experience low self-esteem [2]. The campus should be a nurturing and safe place to teach knowledge and develop academics.

Some pieces of evidence are showing that school bullying has become a global social problem. Major, multi-school surveys of Bullies and Victims Table reported that the rate of bullying among students is about $3 \%-27 \%$, and the rate of victimization among students is about 9\%-27\% [6]. According to the report by Morales et al., more than one-fifth of American students are suffering from school bullying [7]. This is such a serious 
problem, but it was not until 1978 that Olweus began to conduct systematic research and published the book Aggression in the Schools: Bullies and Whipping Boys [8]. In 1987, the European seminar on bullying was held in Norway for the first time, and this seminar made educators all over the world begin to pay attention to school bullying [9]. In 1998, Scotland set up the world's first Anti-Bullying Development Officer and established an Anti-Bullying network in 1999 [10]. In 2003, Australia promulgated the National Safe Schools Framework (NSSF) national policy to prevent and manage bullying and other aggressive behaviors [11]. In 2006, PACER's National Bullying Prevention Center in the United States organized and launched the National Bullying Prevention Month. This event is held every October to educate and raise awareness about bullying prevention. So far, school bullying is still an expanding field of research. This review covers important factors in school bullying and introduces the interventions that schools can take to prevent or reduce school bullying. These could help complement what the existing literature has already done and provide more new ideas.

\section{SCHOOL LEARNING ENVIRONMENT}

The school learning environment is defined as diverse settings for students to learn and interact. The term comprises physical learning environments and the background of cultures [12]. This definition indicates that students are learning in different contexts. However, George and Thomas (2000) suggested that bullying in schools is caused by differences in the composition of students from different backgrounds and related to the physical surroundings, the attitude of teachers, and peer participation [13].

\subsection{Bullying and teachers}

By the study of Veenstra et al. (2014), the antibullying attitude of teachers and their efforts in stopping bullying behavior is related to the level of bullying in the classroom [14]. However, there is very little literature on teachers' attitudes towards school bullying and how to deal with bullying. A lot of evidence shows that teachers are less effective in this area. Research has shown that teachers are not positive about school bullying and provide fewer interventions in the United States [15]. In addition, another research has been found that when bullying incidents occur in the eight classrooms of one public school in metropolitan Toronto, only $18 \%$ of bullying incidents are intervened by teachers. This result is that most teachers lack the awareness of intervening in bullying [16]. Therefore, teachers need to strengthen their anti-bullying attitudes, increase their emphasis on bullying and learn effective interventions to reduce the incidence of school bullying. A national study by the National Education Association of the United States shows that the vast majority of educators concluded that they need additional training on school bullying to learn about relevant knowledge and intervention strategies [17]. In an efficient teaching staff team, the interaction and collaboration between teachers are considered beneficial [18]. Therefore, teachers can exchange ideas and opinions on campus bullying through communication and discussion and formulate corresponding intervention measures based on the discussion process. On the other hand, it is important to convey an anti-bullying class atmosphere. Teachers can establish one-to-one communication with students, promote classroom rules on anti-bullying, conduct related curriculum, and group discussions on school bullying. The above strategies can effectively reduce bullying.

\subsection{Bullying and Peers}

McDonnell et al. point out that peer support positively influences students and even be used as an intervention and prevention for school bullying [19]. Veenstra et al. (2014) mentioned the "Bystander" is one of the reasons why peers hardly intervene in the bullying while they see it [4]. When peers are on the sidelines, they are more likely to want someone else to help the victim or to think things aren't that serious. Peers are afraid to intervene in bullying to help the victim, most likely for fear of retaliation from the abuser. Also, some forms of violence (such as verbal violence, physical violence, cyberbullying) are hard to detect, and they can be seen as a joke [4]. Van der Ploeg (2017) mentions self-efficacy can predict a person's willingness to take a stand against bullying, self-efficacy refers to a person's belief that he or she is capable of accomplishing a task or activity to produce the desired result [20]. Students will only get involved in bullying if they are convinced that they can effectively defend the victims of bullying [21].

\subsection{Physical Surroundings}

The present study determines the characteristics of factors that may lead to bullying behavior in unsupervised out-of-sight spaces to assess physical surroundings. There is a relation between physical disorder and bullying behaviors in the school environment, such as broken windows and poor building conditions [22]. Day \& Midbjer (2007) show that architecture and spatial relations could influence human behavior and social relationships, such as scale and unsupervised out-of-sight spaces [23]. Also, the school environment can affect students, both physically and psychologically, consist of actions, cognitions, thoughts, and habits [24]. Since students' main job is learning, the purpose is to create a positive learning environment to help students learn in a good environment. 


\section{PREVENTION AND INTERVENTION}

United Nations Educational, Scientific, and Cultural Organization (UNESCO) recommend establishing a violence-free place and a safe, educational climate as a global purpose for children in 2018 [25]. Therefore, it is critical to practice proper preventive and to intervene as soon as possible. There have been many studies in the past to prove what can be effective to intervene in school bullying. Many recent analyses have found that some anti-bullying intervention strategies can effectively reduce the emergence of school bullying [26, 27]. This present review mainly focuses on exploring the preventions of the program and peers' participation.

\subsection{Prevention and Program}

The goal of bullying prevention is to decrease the prevalence of bullying behaviors and promote a safe learning environment for students in the school. A metaanalysis of evaluating 100 bullying intervention programs by Farrington and Ttofi showed that most bullying programs effectively decrease bullying incidents in the school [28].

\subsubsection{KiVa Anti-bullying Program}

$\mathrm{KiVa}$ is an anti-bullying program developed by experts at the University of Turku, Finland. The program has been studied rigorously and evidence-based. Its goal is to reduce school bullying behaviors. Data from more than 200 Finnish schools prove that the implementation of this program can effectively reduce various forms of bullying [29]. The program is a whole-school intervention that provides students with corresponding courses, provides parents with a wide range of professional materials and resources, and includes the cultivation of anti-bullying awareness and guiding principles for school educators. The curriculum aims to increase awareness of bullying, increase empathy for the bullied peers, and promote self-efficacy. It consists of discussions, group work, role-play exercises, and related short videos about bullying [28]. The unique feature of the KiVa Anti-bullying Program is that it provides elementary school students with computer simulations, which is an anti-bullying computer game that includes 5 levels. For middle school students, it provides a virtual learning environment, "KiVa Street". Students can visit various buildings related to anti-bullying on this street. For example, they can go to the movie theater to watch movies about school bullying and the library to see the related books [30]. KiVa program has become a popular prevention of school bullying and is now conducted in many countries.

\subsubsection{Olweus Bullying Prevention Program (OBPP)}

The OBPP is the first program that connects with the social movement against bullying problems in Norwegian schools by Olweus (1994), and the main goal of the program was to reduce the occurrence of bullying, then try to prevent and avoid new problems of bullying in schools as much as possible. The intervention assessment was based on data from about 2500 students in 42 primaries to middle schools (4-7 grade) in Bergen. Each grade was collected around 600-700 students of boys and girls by equal distribution [31]. According to the data report, the proportion of students' bullying behavior reduces by half after two years of the program implementation [32]. In general, there are some positive influences about gender, race, and grade in the Olweus Bullying Prevention Program. Still, the OBPP program also may be influenced by background culture and race, result in variable outcomes. Therefore, schools may create preventive measures based on culture, society, and family on student behavior [32].

\subsection{Intervention and Peers}

O'Connell et al. note that half of the bystanders of peers chose not to intervene; a quarter chose to help the victim, and another quarter chose to help the abuser [14]. The studies have shown that peers can effectively reduce the number of bullying episodes [33]. Therefore, the timely intervention of peers is one of the effective ways to stop bullying in school bullying. Peers have an important role in school bullying. For the aspects of preventing bullying, schools can encourage peers to support their victims to increase the likelihood that students will intervene instead of enhancing bullying behavior [34]. It not only improves students' perceptions of bullying but also reduces the influence of the Bystander Effect. In addition, students also can intervene by reporting the occurrence of bullying to get help from teachers. Educating young students on coping with it when they saw the bullying phenomenon is an important way to develop a safe learning environment in school [35].

\section{CONCLUSION}

According to the content above, there is a lot of reliable research that points out the factors influencing school violence and the intervention about school bullying problems. This article spread the basic definition of school bullying and summarized the different aspects that affect school bullying, which involved peers' participation, physical surroundings, and teachers' attitude. On preventing and intervening in school bullying, the KiVa Anti-bullying Program and Olweus Bullying Prevention Program (OBPP) play significant roles in anti-bullying in school. In addition, the peers 
intervened the behaviors of abusers and helped the victims to a certain extent in the context of bullying. Appealing anti-bullying behavior on campus has great practical social meaning to the educational and cognition development of students of all ages.

\section{REFERENCES}

[1] Uba, I., Yaacob, S. N., \& Juhari, R. (2010). Bullying and its' relationship with Depression among Teenagers. Journal of psychology, 1(1), 15-22. https://doi.org/10.1080/09764224.2010.11885441

[2] Limo, S., (2015). Bullying Among Teenagers and Its Effects. Thesis: Turku University of Applied Sciences, Turku, Finlandia.

[3] Marshall, S. A., \& Allison, M. K. (2019). Midwestern misfits: Bullying experienced by perceived sexual and gender minority youth in the Midwestern United States. Youth \& Society, 51(3), 318-338. https://doi.org/10.1177/0044118X17697885

[4] Veenstra, R., Lindenberg, S., Huitsing, G., Sainio, M., \& Salmivalli, C. (2014). The role of teachers in bullying: The relation between antibullying attitudes, efficacy, and efforts to reduce bullying. Journal of Educational Psychology, 106(4), 1135. https://doi.org/10.1037/a0036110

[5] Farrington, D. P., \& Ttofi, M. M. (2009). Schoolbased programs to reduce bullying and victimization. Campbell systematic reviews, 5(1), i148. https://doi.org/10.4073/csr.2009.6

[6] Stassen Berger, K. (2007). Update on bullying at school: science forgotten? Developmental Review, 27(1), 90-126. https://doi.org/10.1016/j.dr.2006.08.002

[7] Morales, D. X., Grineski, S. E., \& Collins, T. W. (2019). School bullying, body size, and gender: An intersectionality approach to understanding US children's bullying victimization. British journal of sociology of education, 40(8), 1121-1137. https://doi.org/10.1080/01425692.2019.1646115

[8] Smith, P. K., \& Brain, P. (2000). Bullying in schools: Lessons from two decades of research. Aggressive Behavior: Official Journal of the International Society for Research on Aggression, 26(1), 1-9. https://doi.org/10.1002/(sici)10982337(2000)26:1<1::aid-ab1>3.0.co;2-7

[9] O’Moore, M., \& Kirkham, C. (2001). Self-esteem and its relationship to bullying behaviour. Aggressive Behavior: Official Journal of the International
Society for Research on Aggression, 27(4), 269 283. https://doi.org/10.1002/ab.1010

[10] James, A. (2010). School bullying (Research Brief). Aggression and Violence Behavior, 15, 112-120. https://doi:10.1016/j.avb.2009.08.007

[11] Cross, D., Epstein, M., Hearn, L., Slee, P., Shaw, T., \& Monks, H. (2011). National safe schools framework: Policy and practice to reduce bullying in Australian schools. International Journal of Behavioral Development, 398-404. https://doi.org/10.1177/0165025411407456

[12] Movchan, S (2018). What Makes a Good Learning Environment. Retrieved from: https://raccoongang.com/blog/what-makes-goodlearning-environment/

[13] George, R., \& Thomas, G. (2000). Victimization among middle and high school students: A multilevel analysis. The High School Journal, 4857. https://doi.org/10.1037/spq0000423

[14] Veenstra, R., Lindenberg, S., Huitsing, G., Sainio, M., \& Salmivalli, C. (2014). The role of teachers in bullying: The relation between anti bullying attitudes, efficacy, and efforts to reduce bullying. Journal of Educational Psychology, 1135-1143. https://doi.org/10.1037/a0036110

[15] Batsche, G. M., \& Knoff, H. M. (1994). Bullies and their victims: Understanding a pervasive problem in the schools. School Psychology Review, 23, 165175.

https://doi.org/10.1080/02796015.1994.12085704

[16] Atlas, R. S., \& Pepler, D. J. (1998). Observations of bullying in the classroom. The journal of educational research, 92(2), 86-99. https://doi.org/10.1080/00220679809597580

[17] Gulemetova, M., Drury, D., \& Bradshaw, C. P. (2014). White House conference on bullying prevention: Findings from the National Education Association's nationwide study of bullying: Teachers' and education support professionals' perspectives. In Student Bullying: Federal Perspectives and Reference Materials (pp. 97-105). Nova Science Publishers, Inc..

[18] David, R., Teddlie, C., \& Reynolds, D. (2000). The international handbook of school effectiveness research. Psychology Press. https://doi.org/10.4324/9780203454404

[19] Tzani-Pepelasi, C., Ioannou, M., Synnott, J., \& McDonnell, D. (2019). Peer support at schools: the buddy approach as a prevention and intervention strategy for school bullying. International journal of 
bullying prevention, 1(2), 111-123. https://doi.org/10.1007/s42380-019-00011-z

[20] Khan, A. S., \& Ullah, I. (2021). Title Comparative Abalysis of Self-Efficacy and Students Scholastic Performance Across Streams. Ilkogretim Online, Vol 20 (Issue 4) pp. 1900-1907. doi 10.17051/ilkonline.2021.04.211

[21] Van der Ploeg, R., Kretschmer, T., Salmivalli, C., \& Veenstra, R. (2017). Defending victims: What does it take to intervene in bullying and how is it rewarded by peers?. Journal of school psychology, 65, $1-10$. https://doi.org/10.1016/j.jsp.2017.06.002

[22] Rezapour, M., Khanjani, N., \& Mirzai, M. (2019). Exploring associations between school environment and bullying in Iran: Multilevel contextual effects modeling. Children and Youth Services Review, 99, 54-63. doi:10.1016/j.childyouth.2019.01.036

[23] Day, C. \& Midbjer, A., (2007), Environment and children: Passive lessons from the everyday environment, From Elsevier Ltd, USA, 040031-2 https://doi.org/10.4324/9780080550978

[24] Septriyani, N. N., Arvanda, E., Kusuma, N. R., \& Isnaeni, H. (2020, May). Architecture and the potential of bullying behavior in elementary school environment. In AIP Conference Proceedings, 1-7. https://doi.org/10.1063/5.0003699

[25] United Nations Educational, Scientific, and Cultural Organisation. (2018). School violence and bullying: global status and trends, drivers and consequences. Paris: UNESCO.

[26] Farrington, D. P., \& Koegl, C. J. (2015). Monetary benefits and costs of the Stop Now and Plan program for boys aged 6 - 11, based on the prevention of later offending. Journal of Quantitative Criminology, 31(2), 263-287. https://doi.org/10.1007/s10940-014-9240-7.

[27] Chalamandaris, A.,\& Piette, D.(2015). School-based anti-bullying interventions: systematic review of the methodology to assess their effectiveness. Aggression and Violent Behavior, 24, 131-174. https://doi.org/10.1016/j.avb.2015.04.004.
[28] Gaffney, H., Farrington, D. P., \& Ttofi, M. M. (2019). Examining the effectiveness of schoolbullying intervention programs globally: A metaanalysis. International Journal of Bullying Prevention, 1(1), 14-31. https://doi.org/10.1007/s42380-019-0007-4

[29] Salmivalli, C., Kärnä, A., \& Poskiparta, E. (2011). Counteracting bullying in Finland: The KiVa program and its effects on different forms of being bullied. International Journal of Behavioral Development, 35(5), 405-411. https://doi.org/10.1177/0165025411407457

[30] Salmivalli, C., Garandeau, C., \& Veenstra, R. (2012). KiVa antibullying program: implications for school adjustment. In G. Ladd \& A. Ryan(Eds.), Peer relationships and adjustment at school (pp. 279-307). Charlotte: Information Age Publishing.

[31] Olweus, D. (1994). Bullying at school: basic facts and effects of a school based intervention program. Journal of child psychology and psychiatry, 35(7), 1171-1190. https://doi.org/10.1111/j.14697610.1994.tb01229.x

[32] Bauer, N. S., Lozano, P., \& Rivara, F. P. (2007). The effectiveness of the Olweus Bullying Prevention Program in public middle schools: A controlled trial. Journal of Adolescent Health, 40(3), 266274.https://doi.org/10.1016/j.jadohealth.2006.10.00 5

[33] Kärnä, A., Voeten, M., Little, T. D., Poskiparta, E., Kaljonen, A., \& Salmivalli, C. (2011). A large-scale evaluation of the KiVa antibullying program: Grade 4-6. Child Development, 82, 311-330. doi :10.1111/j .1467-8624.2010.01557.x

[34] Saarento, S., \& Salmivalli, C. (2015). The role of classroom peer ecology and bystanders' responses in bullying. Child Development Perspectives, 9(4), 201-205. https://doi.org/10.1111/cdep.12140

[35] Lodge, J., \& Frydenberg, E. (2005). The role of peer bystanders in school bullying: Positive steps toward promoting peaceful schools. Theory into practice, 44(4),329-336. https://doi.org/10.1207/s15430421tip4404_6 